\title{
Journal of Oral \& Maxillofacial Research
}

\author{
MANDATORY SUBMISSION FORM
}

Title of article:

\section{A signature of each author below certifies compliance with the following statements:}

Copyright transfer. In consideration of the acceptance of the above work for publication, I do hereby assign and transfer to Journal of Oral \& Maxillofacial Research (JOMR) all rights, title, and interest in and to the copyright in the above-titled work. This assignment applies to all translations of said article as well as to preliminary display/posting of the abstract of the accepted article in electronic form. If any changes in authorship (order, deletions, or additions) occur after the article is submitted, agreement by all authors for such changes must be on file with the Publisher. An author's name may be removed only at his/her written request. (Note: Material prepared by employees of the US government in the course of their official duties cannot be copyrighted.)

Author responsibilities. I attest that:

- The article is original work without fabrication, plagiarism, or fraud;

- The article is not currently under consideration elsewhere and the research reported will not be submitted for publication elsewhere unless a final decision is made by the JOMR that the article is not acceptable;

- I have made a significant scientific contribution to the study and I am thoroughly familiar with the primary data outlined in the article;

- I have read the complete article and take responsibility for the content and completeness of the final submitted article and understand that if the article, or part of the article, is found to be faulty or fraudulent, I share responsibility;

- All clinical images included with the article accurately portray the subjects or material photographed and have not been altered or retouched in any way.

Conflict of interest disclosure. All institutional or corporate affiliations of mine and all funding sources supporting the study are acknowledged. Except as disclosed in the separate enclosed letter, I certify that I have no commercial associations (e.g., consultancies, patent-licensing arrangements, equity interests) that might represent a conflict of interest in connection with the submitted article (letter attached).

Experimental procedures in humans and animals. The Journal endorses the principles embodied in the Declaration of Helsinki and insists that all investigations involving human beings reported in JOMR articles be carried out in conformity with these principles. Authors reporting on their experimental work in humans or animals should also cite evidence in the Method and Materials section of the article that this work has been approved by, respectively, an institutional clinical/human experimentation panel or an institutional animal care and use panel (or equivalent).

Signature of each author is required in the same order as on the article title page. (Multiple forms are acceptable)

$\begin{array}{lll}\text { Signature (1) } & \text { Print name } & \text { Date } \\ \text { Signature (2) } & \text { Print name } & \text { Date } \\ \text { Signature (3) } & \text { Print name } & \text { Date } \\ \text { Signature (4) } & \text { Print name } & \text { Date } \\ \text { Signature (5) } & \text { Print name } & \text { Date }\end{array}$

\section{Corresponding author}

Mailing address

Phone

Fax

E-mail

The Mandatory Submission Form must be signed by all authors, scanned and emailed to the Editorial Assistant info@ejomr.org. 